\title{
Sigmund Freud nos trópicos. A primeira dissertação psicanalítica no mundo lusófono
} (1914)

\author{
Sigmund Freud in the tropics. The first psychoanalytic dissertation in the Portuguese-speaking world (1914)
}

\author{
Autor: Hannes Stubbe \\ Germany: Shaker Verlag; 2011. ISBN 978-3-8440-0174-7
}

\section{Peter Theiss-ABEndRoth ${ }^{1}$}

${ }_{1}$ Psiquiatra e psicanalista.

Recebido: 5/11/2012 - Aceito: 15/11/2012

Theiss-Abendroth P / Rev Psiq Clín. 2013;40(2):81

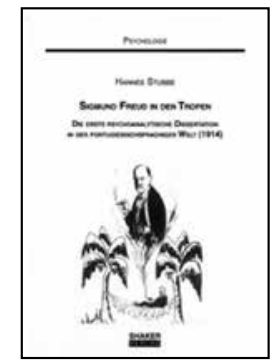

Uma comemoração especial para a história intelectual desta nação está prestes a acontecer: no ano de 2014, o discurso científico sobre a psicanálise no Brasil com-pletará 100 anos. No ano de 1914, o cearense Genserico Aragão de Souza Pinto concluiu seu doutorado na Faculdade de Medicina do Rio de Janeiro, apresentando sua dissertação intitulada Da psicoanalise (A sexualidade nas nevroses) e, com isso, abriu o espaço para a recepção da psicanálise no século a seguir. A referida disser-tação esteve por muito tempo inacessível, até que o alemão Hannes Stubbe, docen-te na área de psicologia antropológica na Universidade de Colônia e na PUC-RJ, a encontrou e veio a divulgá-la em uma reprodução de 129 páginas (1). Hannes Stub-be é um exímio conhecedor do Brasil, tendo ocupado, por muitos anos, diferentes posições no Rio de Janeiro e em São Paulo, assim como em Moçambique e na Chi-na. Ele publicou seu achado na Alemanha e acrescentou a ele um minucioso comen-tário de 70 páginas, o qual esclarece ao leitor tanto o contexto brasileiro quanto o europeu.

Com isso, torna-se claro, o quanto de seu trabalho Pinto deve aos seus orientadores, especialmente a Antônio Austregésilo Rodrigues Lima, o qual, cinco anos depois, publicou um trabalho próprio, nomeado Sexualidade e psiconeurosis. Mas também a Juliano Moreira, apontado como psicoanalista nos agradecimentos de Pinto. Moreira já havia estabelecido contato com a psiquiatria germânica no início do século passa-do. Ali, ele também veio a conhecer Emil Kraepelin, cujo sistema de classificação de doenças psíquicas Moreira tornou conhecido no Brasil ao retornar.

É impressionante o fato de Juliano Moreira, já em 1899, ou seja, antes de realizar a anteriormente citada viagem, ter falado sobre a psicanálise na Faculdade de Medici-na da Bahia. Pinto também se mostra bem informado e familiarizado com uma gran-de quantidade das obras de Freud existentes na época. É verosímil que ele possuís-se conhecimentos básicos da língua alemã, de modo que a barreira entre as línguas romana e germânica - chamada por Hannes Stubbe de "muro latino" - pôde, ao me-nos em parte, ser ultrapassada. Pinto propõe traduções de uma série de termos cen-trais da psicanálise para o português e também classifica na teoria de Freud o que havia de sucessão às teorias de Charcot e Breuer. Ele parece, em geral, notavel-mente familiarizado com os discursos franceses e alemães da sua época, embora não menciona um único trabalho brasileiro sequer. No entanto, ele parece ter consi-derado alguns trabalhos de Freud não diretamente, senão indiretamente através de críticos franceses.

A dissertação de Pinto abrange nove capítulos teóricos, um prefácio, bem como um apêndice com cinco exemplos casuísticos. Seu foco é a compreensão de neuroses e perversões no âmbito da teoria do impulso, da forma que esta existia naquela época. $O$ fato de que sua compreensão teórica não se refere à vivência interior e fantasias do paciente, e muito menos às fantasias edípicas, não minimiza de modo algum o mérito de seu trabalho pioneiro. O núcleo da psicanálise, ou seja, o inconsciente di-nâmico, era, pelo visto, desconhecido por Pinto e seus mestres da época. Assim, a psicanálise para ele vira uma medicina da sexualidade, que se ocupava principal-mente com questões da masturbação e de outras formas insatisfatórias da sexuali-dade. Pinto nos fornece em suas casuísticas visões interessantes de seu trabalho clínico, ao demonstrar seu objetivo principal, que é ajudar seus pacientes, os quais com exceção de uma única pessoa, eram mulheres, a terem uma vida sexual mais satisfatória.

Dentre todas as características do trabalho de Pinto e de seus professores, uma em especial provoca admiração do ponto de vista alemão: sua capacidade de unir no nível universitário o discurso psiquiátrico e psicoanalista. Tal diálogo interdisciplinar falta até hoje na Alemanha e em países como França, Grã-Bretanha, Estados Uni-dos ou países escandinavos este veio a ocorrer somente muito mais tarde.

No volume aqui apresentada, reúnem-se assim diversos méritos pioneiros: o próprio doutorando Pinto, seu meio acadêmico e, por último, mas não menos importante, o editor e comentarista Hannes Stubbe. Espera-se que, a recepção deste trabalho no Brasil, também não termine por ricochetear no tal "muro latino". 


\title{
Comentário do livro
}

\section{Explorando fronteiras da relação mente-cérebro}

\section{Exploring frontiers of the mind-brain relationship}

\section{Editors: Alexander Moreira-Almeida \& Franklin Santana Santos}

Springer: New York, 2012

\author{
HOMERo VALLADA ${ }^{1}$ \\ 1 Professor-Associado, Departamento de Psiquiatria, Faculdade de Medicina, Universidade de São Paulo (FMUSP), São Paulo, SP, Brasil.
}

Recebido: 2/7/2013 - Aceito: 2/8/2013

Vallada H / Rev Psiq Clín. 2013;40(2):82

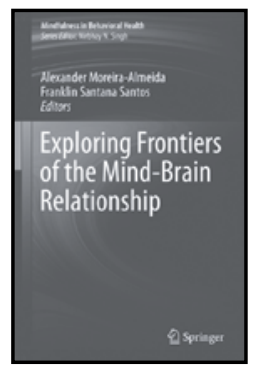

Várias teorias e interpretações religiosas, filosóficas e científicas têm sido propostas ao longo dos séculos para a compreensão da formação e continuidade da consciência do Eu. Mais recentemente, a partir do século XIX, uma nova ideologia genericamente conhecida como "materialismo científico" passa a se estabelecer como a principal linha de orientação na "ciência oficial". Sua premissa é de que tudo na natureza, incluindo a origem do pensamento, é produto oriundo da matéria, da interação entre átomos e moléculas. Apesar de essa abordagem ser direta, objetiva e compreensível, ela ainda não foi capaz de explicar alguns fenômenos relacionados com a mente humana. A própria consciência do Eu continua sendo um grande enigma e mistério.

Com o intuito de apresentar um amplo debate sobre esse assunto, em nível acadêmico de forma rigorosa, o psiquiatra Alexander Moreira-Almeida, que lidera o principal grupo em saúde e espiritualidade no Brasil, e o geriatra Franklin Santana Santos, referência nacional no manejo de cuidados paliativos e tanatologia, convidaram importantes pensadores e pesquisadores para um simpósio internacional. As principais ideias e discussões apresentadas foram editadas no livro "Exploring Frontiers of Mind-Brain Relationship" (Explorando as fronteiras da relação mente-cérebro) publicado pela Springer em 2012.

O livro está dividido em 12 capítulos (16 autores) e organizado em quatro partes. A primeira parte aborda os aspectos filosóficos e históricos, seguidos de explicações da física, que inclui conceitos de física quântica. Em seguida, são discutidos os estudos de neuroimagem funcional em estados místico e meditativo e, em sua última parte, são apresentados relatos de diferentes experiências humanas como linha de investigação científica promissora na compreensão da relação mente-cérebro.

Os capítulos são bem escritos, claros, concisos, com linguagem acessível para o público em geral. Apesar de poderem ser lidos individualmente, o trabalho de edição integrando os diferentes capítulos faz com que o leitor possa acompanhar essa trajetória, conduzindo-o para o ponto principal do livro, que é a crítica da utilização de uma abordagem puramente materialista e reducionista da ciência, para compreender determinados fenômenos do comportamento e da mente humana. Os autores procuram, em suas diferentes linhas de pensamento, desenvolver os argumentos do uso inadequado dessa abordagem.

O livro também comenta sobre a questão da espiritualidade/ religiosidade na vida das pessoas. Já existe um grande número de trabalhos científicos demonstrando que as pessoas mais religiosas/ espiritualizadas ficam menos doentes ou recuperam mais rapidamente a saúde quando comparadas com a população geral. Entretanto, estudos para compreender especificamente o que significam as vivências místicas, religiosas, espirituais ou outras experiências anômalas ou estados alterados da consciência são ainda muito limitados e em pequeno número.

A título de ilustração, são relatados alguns tipos de experiências que encontramos registrados em diferentes culturas e diferentes períodos da humanidade. São fenômenos que ocorrem em distintos momentos da vida humana, tais como relatos de crianças que descrevem com detalhes suas memórias sugestivas de vidas passadas, crianças/adultos que alegam se comunicar com pessoas já falecidas (o que se convencionou chamar de mediunidade), adultos em estados místicos ou meditativos com experiências perceptivas anômalas (experiência fora do corpo, clarividências, entre outros), relatos de pessoas que tiveram paradas cardiorrespiratórias ou ainda eventos graves com hipofluxo cerebral (experiências de quase morte), ou ainda vivências daqueles que estão morrendo (experiências do fim da vida).

A observação desses diferentes fenômenos que acontecem ao longo da vida de uma importante parcela da população, como comentamos antes, tem sido relatada há milênios e talvez a diferença é que hoje esses fenômenos são mais bem descritos e registrados. Entretanto, esses relatos da experiência humana continuam sendo negligenciados do ponto de vista científico.

Parabenizo os editores e autores por esse trabalho e recomendo a leitura desse livro não só para aqueles interessados nesse tema, mas também para aqueles que querem ter uma visão mais ampla sobre a variedade de experiências humanas e suas implicações na prática clínica. Uma tradução em português seria também muito bem-vinda para atingir um público ainda maior no Brasil... e além-mar. 